\title{
Cost-effectiveness of indacaterol/glycopyrronium in comparison with salmeterol/fluticasone combination for patients with moderate-to-severe chronic obstructive pulmonary disease: a LANTERN population analysis from Singapore
}

Augustine $\underline{T e}^{1}$, FRCP, FCCP, Wai Leng $\underline{\text { Chow }}^{2}$, MBBS, GDFM, Colin $\underline{B u r k e}^{3}$, MPharm, MSc, Basavarajaiah Guruprasad ${ }^{4}$, MBBS, MD

\begin{abstract}
INTRODUCTION In light of the growing evidence base for better clinical results with the use of the dual bronchodilator indacaterol/glycopyrronium (IND/GLY) over inhaled corticosteroid-containing salmeterol/fluticasone combination (SFC), this study aimed to evaluate the cost-effectiveness of IND/GLY over SFC in patients with moderate-to-severe chronic obstructive pulmonary disease (COPD) who are at low risk of exacerbations, in the Singapore healthcare setting.

METHODS A previously published patient-level simulation model was adapted for use in Singapore by applying local unit costs. The model was populated with clinical data from the LANTERN and ECLIPSE studies. Both costs and health outcomes were predicted for the lifetime horizon from a payer's perspective and were discounted at $3 \%$ per annum. Costs were expressed in 2015 USD exchange rates. Uncertainty was assessed through probabilistic sensitivity analysis. RESULTS Compared to SFC, use of IND/GLY increased mean life expectancy by 0.316 years and mean quality-adjusted life years (QALYs) by 0.246 years, and decreased mean total treatment costs (drug costs and management of associated events) by USD 1,474 over the entire lifetime horizon. IND/GLY was considered to be $100 \%$ cost-effective at a threshold of $1 \times$ gross domestic product per capita. The cost-effectiveness acceptability curve showed that IND/GLY was 100\% cost-effective at a willingness-to-pay threshold of USD 0 (additional cost) when compared to SFC.

CONCLUSION IND/GLY was estimated to be highly cost-effective compared to SFC in patients with moderate-to-severe COPD who are not at high risk of exacerbations in the Singapore healthcare setting.
\end{abstract}

Keywords: COPD, cost-effective, indacaterol/glycopyrronium, salmeterol/fluticasone, Singapore

\section{INTRODUCTION}

Morbidity and mortality associated with chronic obstructive pulmonary disease (COPD) are considerably high. According to the Global Burden of Disease Study, COPD was the fifth leading cause of years lived with disability and the third leading cause of death in 2010. ${ }^{(1,2)}$ Currently, COPD is the tenth leading cause of death in Singapore. ${ }^{(3)}$ Across the Asia-Pacific region, the overall prevalence of COPD was estimated to be $6.2 \%$ in 2012, and in Singapore alone, this rate was $5.9 \%{ }^{(4)}$

The economic burden of COPD in Singapore is considerably high. During 2005-2009, the total direct medical costs associated with COPD were estimated to be USD 9.9 million per year, with hospitalisations accounting for over $70 \%$ of the amount, ${ }^{(5)}$ implying that reducing hospitalisations or, specifically, reducing the frequency of exacerbations and pneumonia can significantly decrease the associated financial burden.

It has been observed that approximately $70 \%$ of patients have COPD of Global Initiative for Chronic Obstructive Lung Disease (GOLD) Stage I or II (largely falling into the GOLD Group B category) at the time of diagnosis. ${ }^{(6)}$ The GOLD guidelines recommend the use of inhaled corticosteroids (ICSs) in combination with a long-acting $\beta 2$-adrenergic agonist (LABA) and/ or a long-acting muscarinic antagonist (LAMA) for patients with severe or very severe airflow limitation and/or $\geq 2$ exacerbations per year or $\geq 1$ exacerbation per year leading to hospital admission (Groups C and D). ${ }^{(7)}$ Despite these recommendations, ICSs are widely used for as many as one-third of GOLD Groups A and $B$ patients with mild or moderate airflow limitation and/or 0-1 exacerbation per year with no hospitalisation for exacerbation. ${ }^{(8-13)}$ The overuse of ICSs increases the risk of side effects in these patients, ${ }^{(7,14-18)}$ thereby increasing the healthcare costs of COPD management. ${ }^{(7,8,13,14)}$

The dual bronchodilator indacaterol/glycopyrronium (IND/GLY), a combination of LABA (indacaterol) and LAMA (glycopyrronium), is approved for maintenance treatment of COPD in Singapore. The use of IND/GLY is indicated for patients who remain symptomatic despite being on long-acting monotherapy and have a history of infrequent exacerbations. ${ }^{(7)}$ Randomised controlled trials, such as ILLUMINATE(19) and LANTERN, ${ }^{(20)}$ have compared IND/GLY to the LABA/ICS-containing combination of salmeterol/fluticasone (SFC), considering them as appropriate comparators, in largely low-risk but symptomatic patient

${ }^{1}$ Department of Respiratory and Critical Care Medicine, Changi General Hospital, ${ }^{2}$ Health Services Research, Eastern Health Alliance, Singapore, ${ }^{3} \mathrm{HE}$ Modelling, Novartis Ireland Ltd, Ireland, ${ }^{4}$ Medical Affairs, Novartis Singapore Pte Ltd, Singapore

Correspondence: Dr Guruprasad Basavarajaiah, Senior Medical Advisor, Novartis Retina, Respiratory and Alcon Pharma, Singapore and Asian Emerging Markets, 20 Pasir Panjang, Singapore 117439. guru.prasad@novartis.com 


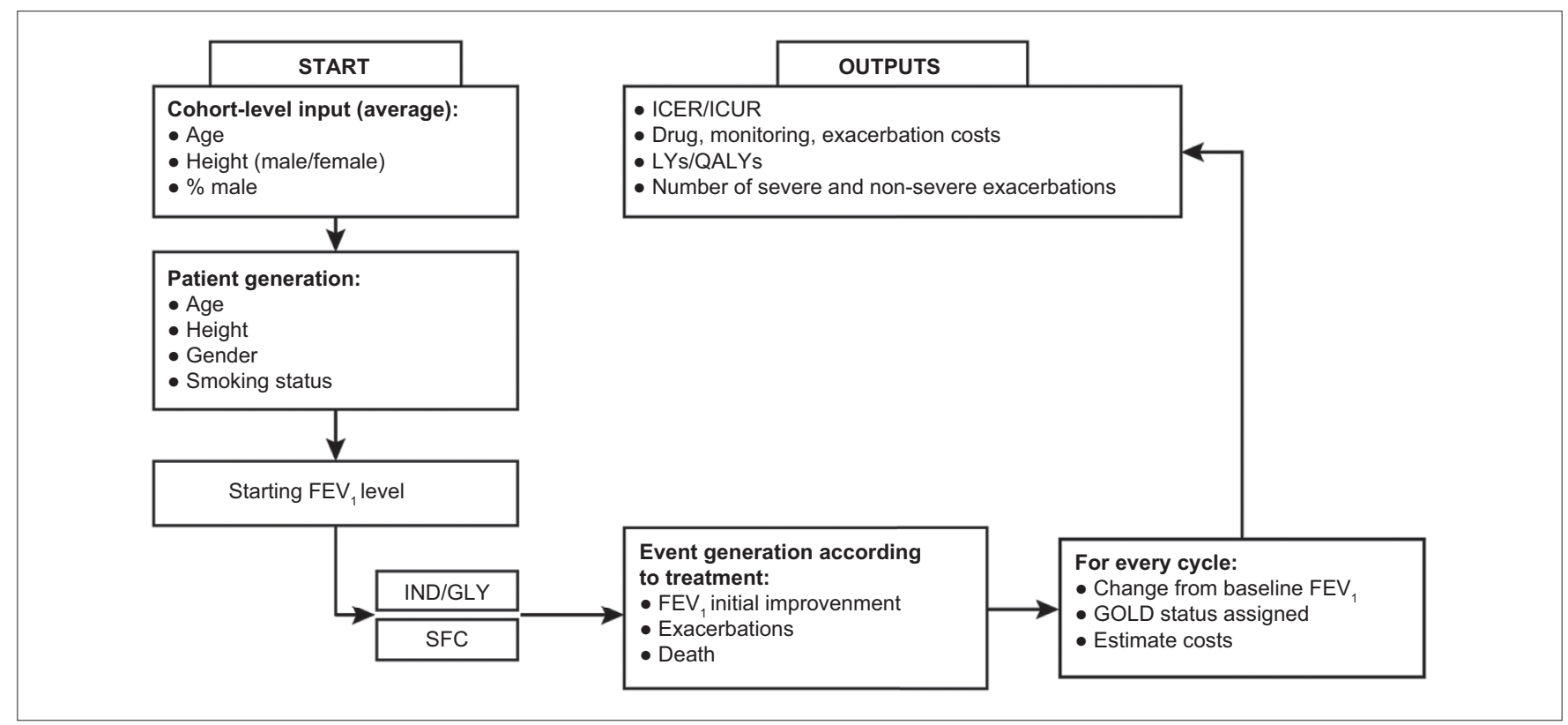

Fig. 1 Flowchart shows the schematic model used for the comparison of costs and outcomes of COPD patients managed with IND/GLY versus SFC. COPD: chronic obstructive pulmonary disease; $\mathrm{FEV}_{1}$ : forced expiratory volume in $1 \mathrm{~s}$; GOLD: Global Initiative for Chronic Obstructive Lung Disease; ICER: incremental cost-effectiveness ratio; ICUR: incremental cost-utility ratio; IND/GLY: indacaterol/glycopyrronium; LY: life year; QALY: quality-adjusted life year; SFC: salmeterol/fluticasone

populations with moderate-to-severe COPD. ${ }^{(19,20)}$ Although the guideline recommends the use of SFC for severe or very severe COPD (GOLD Groups C and/or D) with a history of repeated or severe exacerbations, ${ }^{(7)}$ it is commonly used in low-risk patients in real-life practice. ${ }^{(8-13)}$ Evidence from the recently concluded LANTERN trial suggests that when compared to SFC, IND/GLY significantly reduced the rate of moderate or severe exacerbations by $31 \%$ in symptomatic GOLD Group B and D (53\% and $47 \%$ of the total population, respectively) patients with a history of $\leq 1$ exacerbation in the previous year (based on modified medical research council scores and lung function criteria). ${ }^{(20)}$ In addition, the incidence of pneumonia was observed to be lower with IND/GLY than with SFC. Based on these new clinical findings from the LANTERN trial, the current study aimed to evaluate the pharmacoeconomics of IND/GLY and SFC among patients with moderate-to-severe COPD and a history of $\leq 1$ exacerbation in the previous year in a Singapore healthcare setting.

\section{METHODS}

Changi General Hospital (CGH) is a public, tertiary acute hospital located in the eastern region of the island state of Singapore. ${ }^{(21)}$ It is a 1,000-bedded hospital that serves a population of about one million people. Singapore healthcare has a mixed financing model, comprising a combination of out-of-pocket payments by the individual, individual insurance, mandatory personal medical savings accounts (Medisave), mandatory health insurance that covers catastrophic inpatient admission episodes (MediShield Life) and government subsidies for healthcare services through public healthcare institutions..$^{(22)}$

A previously published patient-level simulation model ${ }^{(23,24)}$ was used to compare the costs and outcomes of patients with COPD managed with IND/GLY and SFC from the public healthcare perspective in Singapore (Fig. 1). Data from published trials was used for validating the model, as described in the previously published paper. ${ }^{(23)}$ A cohort of patients ( $\left.n=100,000\right)$ was generated, where each patient was assigned a unique set of baseline characteristics using mean values and variance-covariance matrices derived from patient-level trial data. Using Monte Carlo simulation methods, a simulated patient moved through the model. The patient experienced clinical events, complications and progression at probabilities based on their simulated baseline characteristics and treatment-specific risk modifiers. The model incorporated the effects of forced expiratory volume in one second $\left(\mathrm{FEV}_{1}\right)$ decline, exacerbation and pneumonia event rates. For each patient, the initial $\mathrm{FEV}_{1}$ score was based on their simulated characteristics and the treatment they were distributed to. The decline in $\mathrm{FEV}_{1}$ was calculated as described by Falaschetti et $\mathrm{al}^{(25)}$ and the European Community for Steel and Coal. ${ }^{(26)}$ As FEV 1 declined, patients moved into GOLD states of increasing severity. Thus, disease severity was determined at each cycle of six months based on GOLD states. A simulated patient could die according to life table mortality probabilities if their simulated $\mathrm{FEV}_{1}$ fell to less than 0 or if a patient survived to 100 years of age.

Detailed descriptions of the parameters used in the model have been provided in the previously published paper. ${ }^{(23)}$ However, two parameters, the Transition Dyspnea Index and St George's Respiratory Questionnaire, were not considered for the present cost-effectiveness analysis, as these were more related to treatment switching. Since the comparator was an ICS combination, pneumonia rates and costs were later added to the model due to the established evidence of risk of pneumonia with ICS use. ${ }^{(17)}$

The cycle lengths were set to six months to match the study duration of the LANTERN trial and the time horizon was a lifetime. Results were also presented for one year, three years, five years and ten years to better inform healthcare policies on 
the short-, medium- and long-term benefits of the use of IND/ GLY over SFC in Singapore. Health outcomes were expressed in terms of life-years (LYs) and quality-adjusted LYs (QALYs), and were used to calculate the incremental cost-effectiveness ratios and the incremental cost-utility ratios.

The model was updated with the population and clinical data from the LANTERN study ${ }^{(20)}$ and adapted for use in the Singapore healthcare setting. The LANTERN study was a 26-week, multicentre, randomised, double-blind, double-dummy, parallelgroup study, which aimed to assess the efficacy, safety and tolerability of IND/GLY when compared to SFC in patients with moderate-to-severe COPD with a history of $\leq 1$ exacerbation in the previous year. The population and efficacy inputs used for comparison are summarised in Tables I and II.

Since the analysis took on the healthcare provider's perspective, only direct costs were included, which comprised COPD drugs, maintenance costs, and costs related to exacerbations and pneumonia events. Maintenance costs were defined as nonexacerbation-related costs after deducting the costs of COPD drugs. Inpatient costs were based on actual admission gross bills incurred at $\mathrm{CGH}$ for the respective disease-related groups. Outpatient costs were based on specialist treatment costs at $\mathrm{CGH}$.

Table I. Population inputs from the LANTERN trial. ${ }^{(20)}$

\begin{tabular}{|ll|}
\hline Baseline characteristic & Mean \pm SD/\% \\
\hline Age at baseline $(\mathbf{y r})$ & $65.1 \pm 7.93$ \\
\hline Height $(\mathbf{c m})$ & $165.7 \pm 7.16$ \\
\hline Male gender & 90.7 \\
\hline Body mass index $\left(\mathbf{k g} / \mathbf{m}^{2}\right)$ & $23.80 \pm 3.77$ \\
\hline Patients according to disease severity & \\
\hline GOLD I (80\%-100\%) & 0.1 \\
\hline GOLD II (50\%-80\%) & 52.2 \\
\hline GOLD III (30\%-50\%) & 46.4 \\
\hline GOLD IV (0\%-30\%) & 1.3 \\
\hline
\end{tabular}

GOLD: Global Initiative for Chronic Obstructive Lung Disease; SD: standard deviation
In addition, costs of primary care follow-up were estimated from the Primary Care Survey 2010. ${ }^{(27)}$

Resource use estimates were obtained from a German study $^{(28)}$ and, where appropriate, provided by local experts. All resource use estimates were validated by local experts for use in the Singapore healthcare setting (Table III). Singapore-specific unit costs were applied to the resource use data to calculate the costs in USD. The cost base year was 2015. The exchange rate used was 1 USD = 1.4 SGD. ${ }^{(29)}$ Aggregated maintenance costs for different severity stages were estimated as follows (in USD): mild (USD 82.2); moderate (USD 83.4); severe (USD 145.6); and very severe (USD 229.5). The total costs were assessed to be USD 57.1 for non-severe exacerbations and USD 1,661.0 for severe exacerbations. Both costs and health outcomes were annually discounted at a rate of $3 \%$.

The rates of mild, moderate and severe COPD exacerbations were obtained from the LANTERN study. The baseline exacerbation rate for patients treated with IND/GLY with no previous history of exacerbations was estimated to be 0.23 (95\% confidence interval [Cl] 0.16-0.33). However, increase in the future risk of exacerbations, associated with a history of previous exacerbations, ${ }^{(30-34)}$ was estimated using data from the ECLIPSE study (which included both exacerbators and non-exacerbators): $2.24(95 \% \mathrm{Cl} 1.17-4.47)$ for patients with a history of one exacerbation; and $5.72(95 \% \mathrm{Cl} 2.84-7.31)$ for patients with a history of $\geq 2$ exacerbations in the past year. ${ }^{(30)}$ Data from the LANTERN study could not be used, as it excluded patients who were frequent exacerbators ( $\geq 2$ exacerbations in the past year). The exacerbation rate ratio for SFC versus IND/GLY was estimated to be 1.45 (95\% Cl 1.10-1.97), which was based on data from the LANTERN trial (pertaining to both patients with and without exacerbation history). This rate ratio was applied over the lifetime horizon of the model and to all severity stages. As also mentioned in Asukai et al, ${ }^{(23)}$ it was assumed that continued treatment returned a continued treatment effect based on the results of the one-year SPARK trial ${ }^{(35)}$ and FLAME trial. ${ }^{(36)}$ It was also

Table II. Efficacy inputs derived from the LANTERN trial. ${ }^{(20)}$

\begin{tabular}{|c|c|c|}
\hline \multirow[t]{2}{*}{ Parameter } & \multicolumn{2}{|c|}{ Least square means (95\% Cl) } \\
\hline & IND/GLY & SFC \\
\hline 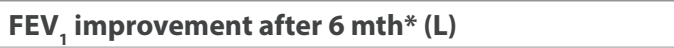 & $0.162(0.129-0.195)$ & $0.055(0.022-0.088)$ \\
\hline Pneumonia rate $^{\dagger}$ & $0.017(0.003-0.040)$ & $0.057(0.028-0.096)$ \\
\hline \multicolumn{3}{|l|}{ Exacerbation rate ${ }^{\ddagger}$} \\
\hline No history of exacerbations & $0.230(0.164-0.332)$ & $0.334(0.262-0.409)$ \\
\hline 1 exacerbation in past year & $0.515(0.358-0.739)$ & $0.747(0.587-0.916)$ \\
\hline$\geq 2$ exacerbations in past year & $1.316(0.915-1.888)$ & $1.908(1.499-2.340)$ \\
\hline Probability of severe/non-severe exacerbation (\%) & Non-severe & Severe \\
\hline GOLDI & 100.0 & 0.0 \\
\hline GOLD ॥ & 94.5 & 5.5 \\
\hline GOLD III & 92.4 & 7.6 \\
\hline GOLD IV & 87.5 & 12.5 \\
\hline
\end{tabular}

*Improvement in trough $\mathrm{FEV}_{1}$ from baseline. †Annualised rate of pneumonia-related hospitalisation. $¥$ Annualised rate of moderate-to-severe exacerbation. $\mathrm{Cl}$ : confidence interval; $\mathrm{FEV}_{1}$ : forced expiratory volume in $1 \mathrm{~s}$; GOLD: Global Initiative for Chronic Obstructive Lung Disease; IND/GLY: indacaterol/glycopyrronium; SFC: salmeterol/fluticasone 
Table III. Resource inputs and costs used in the analysis.

\begin{tabular}{|c|c|c|c|c|c|c|c|}
\hline \multirow[t]{2}{*}{ Variable } & \multicolumn{4}{|c|}{$\begin{array}{l}\text { Annual resource rates } \\
\text { for maintenance }\end{array}$} & \multicolumn{2}{|c|}{$\begin{array}{l}\text { Per episode for } \\
\text { exacerbations }\end{array}$} & \multirow[t]{2}{*}{ Unit cost* (USD) } \\
\hline & Mild & Moderate & Severe & $\begin{array}{l}\text { Very } \\
\text { severe }\end{array}$ & Non-severe & Severe & \\
\hline Influenza vaccination (no. of injections) & 1.0 & 1.0 & 1.0 & 1.0 & - & - & 11.40 \\
\hline Theophylline (days/patient) & 0.0 & 122.10 & 161.80 & 159.10 & - & - & 0.10 \\
\hline Mucolytics (days/patient) & 0.0 & 39.70 & 48.30 & 80.60 & - & - & 0.50 \\
\hline Oral corticosteroids (days/patient) & 0.0 & 21.50 & 23.70 & 78.50 & 5.0 & 5.0 & 0.40 \\
\hline Oxygen (\% patients) & 0.0 & 0.0 & 0.0 & 0.20 & - & - & 454.20 \\
\hline GP visit* & 2.0 & - & - & - & - & - & 45.10 \\
\hline Specialist outpatient visit & - & 1.0 & 3.0 & 4.0 & 1.0 & - & 50.70 \\
\hline Spirometry (no. of tests) & 1.0 & 1.0 & 1.0 & 1.0 & - & - & 62.90 \\
\hline Antibiotics (days/patient) & - & - & - & - & 5.0 & 5.0 & 0.90 \\
\hline ER visit with admission & - & - & - & - & - & 1.0 & 82.10 \\
\hline Non-ICU hospital stay & - & - & - & - & - & 1.0 & $1,572.40$ \\
\hline Pneumonia cost $^{\ddagger}$ & - & - & - & - & - & - & $3,137.90$ \\
\hline \multicolumn{8}{|l|}{ Drug cost (daily) } \\
\hline IND/GLY & - & - & - & - & - & - & 1.38 \\
\hline SFC & - & - & - & - & - & - & 1.44 \\
\hline
\end{tabular}

*Cost base year was calculated based on details available as of 27 August 2015. †GP visit included treatment/investigations and consultation. ¥Refers to the occurrence of a pneumonia event. ER: emergency room; ICU: intensive care unit; IND/GLY: indacaterol/glycopyrronium; GP: general practitioner; SFC: salmeterol/fluticasone

Table IV. Incremental results for the base case cost-effectiveness analysis for IND/GLY versus SFC.

\begin{tabular}{|c|c|c|c|c|c|}
\hline \multirow[t]{2}{*}{ Variable } & \multicolumn{5}{|c|}{ Time horizon } \\
\hline & $1 \mathrm{yr}$ & $3 y r$ & $5 \mathrm{yr}$ & $10 \mathrm{yr}$ & Lifetime \\
\hline Total incremental cost (USD) & -104 & -360 & -606 & $-1,084$ & $-1,474$ \\
\hline Drug & -22 & -56 & -81 & -110 & -69 \\
\hline Maintenance & -7 & -21 & -31 & -53 & -39 \\
\hline Non-severe exacerbation & -4 & -25 & -53 & -115 & -179 \\
\hline Severe exacerbation & -9 & -52 & -114 & -255 & -412 \\
\hline Pneumonia & -62 & -206 & -326 & -551 & -776 \\
\hline Incremental LY & 0.000 & 0.008 & 0.025 & 0.091 & 0.316 \\
\hline Incremental QALY & 0.001 & 0.012 & 0.030 & 0.089 & 0.246 \\
\hline ICER & Dominant & Dominant & Dominant & Dominant & Dominant \\
\hline ICUR & Dominant & Dominant & Dominant & Dominant & Dominant \\
\hline
\end{tabular}

ICER: incremental cost-effectiveness ratio; ICUR: incremental cost-utility ratio; IND/GLY: indacaterol/glycopyrronium; LY: life year; QALY: quality-adjusted life year; SFC: salmeterol/fluticasone

assumed that the treatment effect observed in the LANTERN trial was applicable to patients who later experienced more frequent exacerbations. Pooled data of indacaterol trials was used to derive the probabilities of severe or non-severe exacerbations based on disease severity in terms of the patient's GOLD stage. ${ }^{(37-39)}$

The regression method reported by Rutten-van Mölken et al ${ }^{(40)}$ and Price et $\mathrm{al}^{(24)}$ was used to derive the utility values. Inputs for the regression model were taken from within the model or assumed from the ECLIPSE study where not available. ${ }^{(30)}$ The following regression equation was used to calculate the utility value at each cycle, where the number of concomitant diseases was assumed to be four per person: Utility value $=0.688+($ gender $\times 0.057)+$ $\left(\mathrm{FEV}_{1} \%\right.$ predicted $\left.\times 0.003\right)+($ emergency visits in the last year $\times$ $-0.029)+($ hospital admission in the last year $x-0.02)+$ (number of concomitant diseases $x-0.01)+($ body mass index $x-0.003)$.
To accurately reflect the characteristics of patients with COPD in Singapore, age-related mortality rates were calculated using the general population mortality rates in Singapore, ${ }^{(41)}$ though these were based on population characteristics from the LANTERN study. COPDrelated mortality rates were calculated by applying a hazard ratio of 1.02 (deduced from the OLIN COPD study), ${ }^{(42)}$ which described the increased risk of death associated with a decline in $\mathrm{FEV}_{1}{ }^{(42)}$ This hazard ratio was adjusted based on the predicted decline in $\mathrm{FEV}_{1}$ for an individual patient ${ }^{(25)}$ using the following equation, where the mortality rate was based on $\mathrm{FEV}_{1}$ status and not the exacerbation rate: Probability of death $=$ (general population risk for the appropriate age and gender) $\times 1.02$ (the decline in $\mathrm{FEV}_{1} \%$ predicted).

Probabilistic sensitivity analysis was conducted to assess the uncertainty with regard to the estimated values. The analysis was performed using 10,000 patients and 1,000 cohorts. 


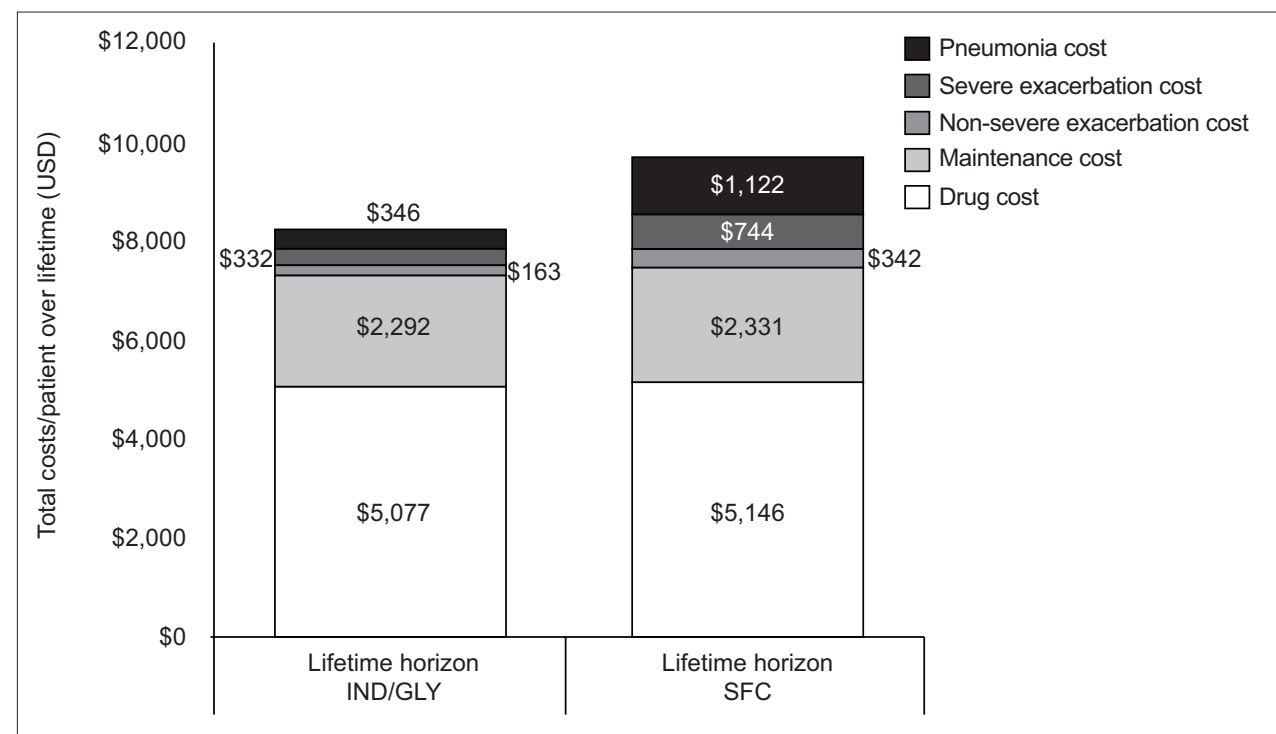

Fig. 2 Bar chart shows costs per patient (in USD) over the lifetime horizon for IND/GLY and SFC. IND/GLY: indacaterol/glycopyrronium; SFC: salmeterol/ fluticasone

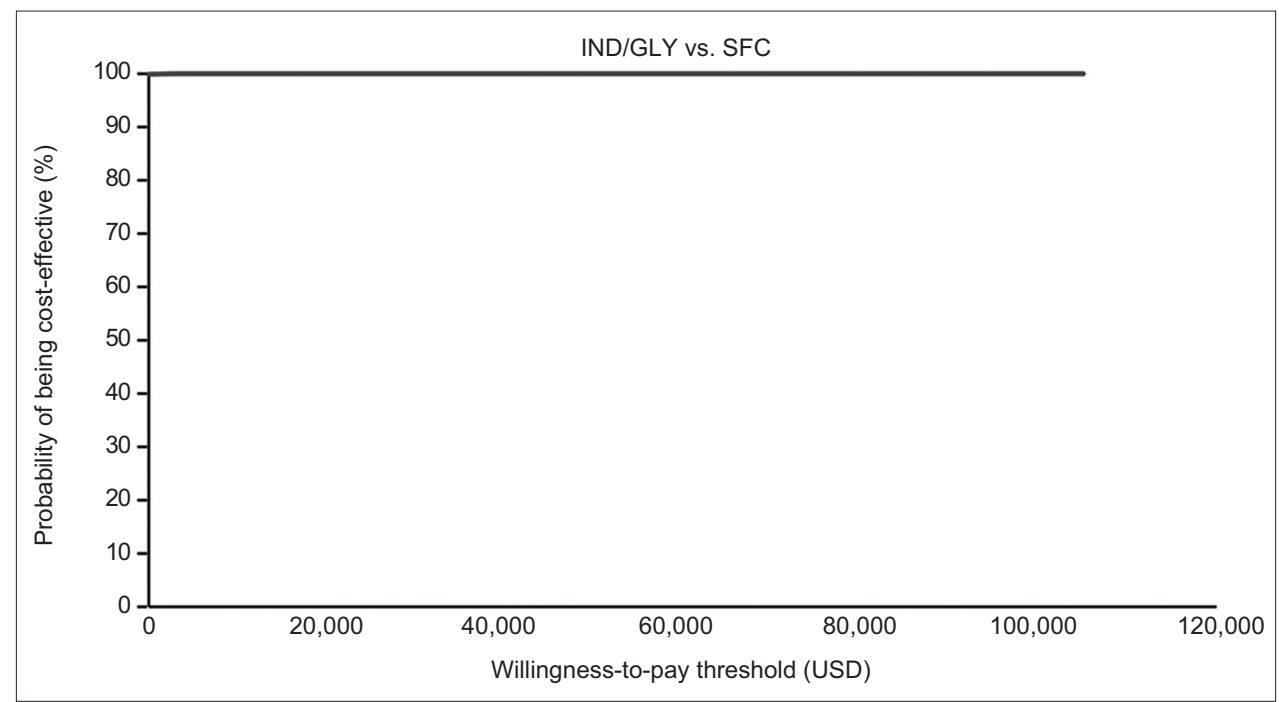

Fig. 3 Chart shows the cost-effectiveness acceptability curve of IND/GLY and SFC. IND/GLY: indacaterol/glycopyrronium; SFC: salmeterol/fluticasone

\section{RESULTS}

Results of the base case cost-effectiveness analysis of all time horizons are presented in Table IV. Our analysis indicated that patients on IND/GLY had better health-related quality of life (incremental QALYs 0.246) and experienced gain in LYs (incremental LYs 0.316) when compared to those receiving SFC. This was accompanied by cost savings of USD 1,474 compared to SFC over the entire lifetime horizon. These results indicate that IND/GLY is a dominant treatment strategy over SFC, being more effective and less costly.

On comparing IND/GLY and SFC, the use of IND/GLY led to cost savings per patient over a lifetime for drug costs (USD 5,077 vs. USD 5,146), maintenance costs (USD 2,292 vs. USD 2,331), non-severe exacerbation costs (USD 163 vs. USD 342), severe exacerbation costs (USD 332 vs. USD 744) and pneumonia costs (USD 346 vs. USD 1,122) (Fig. 2). With these, total cost savings per patient over a lifetime was observed to be higher with the use of IND/GLY over SFC (USD 8,210 vs. USD 9,685).
Results of the probabilistic sensitivity analysis showed that at a threshold of zero, in $99.98 \%$ of simulations, the use of IND/GLY resulted in lower costs and more QALYs than SFC. The cost-effectiveness acceptability curve showed that IND/GLY was $100 \%$ cost-effective at a willingness-to-pay threshold of USD 0 (additional cost) when compared to SFC (Fig. 3).

\section{DISCUSSION}

This analysis demonstrated the economic value of IND/GLY in the Singapore healthcare setting at $\mathrm{CGH}$ based on data from the LANTERN and ECLIPSE studies. The base case analysis results indicated that IND/GLY was a dominant (more effective and less costly) treatment strategy over SFC in a Singapore patient population that was not at high risk for exacerbation, similar to that of the LANTERN study. This conclusion was based on the WHO-CHOICE (World Health Organization-Choosing Interventions that are Cost-Effective) method developed using gross domestic product (GDP) per capita $(<1$ GDP per capita: 
very cost effective; $1-3 \times$ GDP per capita: cost effective; $>3 \times$ GDP per capita: not cost effective; Singapore's GDP per capita in 2015 was USD 56,285). ${ }^{(43,44)}$ IND/GLY was observed to be $100 \%$ cost-effective at a threshold of $1 \times$ GDP per capita.

IND/GLY was associated with lower drug costs, maintenance costs, non-severe exacerbation costs, severe exacerbation costs and much lower pneumonia costs when compared to SFC for the treatment of patients with COPD in Singapore over a lifetime horizon. The results were consistent across the various time horizons analysed - one, three, five and ten years - with greater cost savings and more benefits, in terms of QALYs and LYs, observed at the extended time horizons.

To the best of our information, this is the first study to assess the cost-effectiveness of IND/GLY versus SFC in a broad patient population with COPD (patients with moderate-to-severe COPD with a history of $\leq 1$ exacerbation in the previous year) in the Singapore healthcare setting. However, this analysis has several limitations. First, the LANTERN trial had a short study duration of 26 weeks, which was not adequate to measure exacerbations as a primary endpoint. Second, although the LANTERN trial included a broad patient population, patients who had frequent exacerbations (> 1 exacerbation in the prior year) were not included. Third, this analysis was based on a single randomised controlled clinical trial. A comprehensive assessment to extrapolate our findings to the entire patient population with COPD would require inclusion of data points of IND/GLY versus SFC from other sources (e.g. multiple trials or data from real-world studies that are specific to the Singapore COPD population). Fourth, data from the ECLIPSE study was used to link exacerbation history and the likelihood of future exacerbations, instead of data from the LANTERN trial, which provided all the other population and clinical data for populating the model.

Due consideration was given to the fact that the population inputs of the LANTERN trial should be used, as this would best reflect and model the observed outcomes of the LANTERN trial. The LANTERN trial population comprised GOLD Group B patients (53\% of the total population). As discussed earlier, approximately $70 \%$ of patients were classified as GOLD Stage I or II (largely GOLD Group B) at the time of diagnosis. ${ }^{(6)}$ However, in the real world, a high proportion (approximately 50\%) of these GOLD Group B patients are managed with ICS-inclusive options, ${ }^{(9)}$ even though the use of ICS-containing combinations such as SFC are deemed inappropriate according to the GOLD guidelines of 2015 and 2017. (7,45) Hence, although these results cannot be applied to the overall COPD population, it is quite relevant to a significant proportion of COPD patients in the real world. Furthermore, these populations and clinical inputs were validated by local experts for use in the Singapore patient population. Lastly, with regard to limitations, although resource utilisation rates, particularly for drug use, were estimated from a German study, ${ }^{(28)}$ local experts adapted these to local clinical management practices.

The findings of our study are similar to those reported in other healthcare settings. The earlier cost-effectiveness analyses conducted in Swedish ${ }^{(24)}$ and Greek ${ }^{(46)}$ healthcare settings (both based on clinical results from the ILLUMINATE trial) ${ }^{(19)}$ also demonstrated that IND/GLY was a dominant treatment over SFC in patients with COPD with and without a history of exacerbations. Further, a recently published cost-effectiveness analysis based on the LANTERN data reported that IND/GLY was more effective and less costly than SFC for patients with a history of $\leq 1$ exacerbation in the previous year in four healthcare settings, namely Canada, France, Italy and Portugal. ${ }^{(47)}$

In conclusion, this study suggests that IND/GLY is costeffective when compared to SFC for patients with no exacerbation or those at low risk of exacerbation, similar to the patient population assessed in the LANTERN study, over the lifetime horizon in the Singapore healthcare setting. With the use of IND/GLY over SFC, health benefits were observed in terms of QALYs and LYs and there were cost savings in terms of drug, maintenance, exacerbation and pneumonia costs. This indicates that the use of IND/GLY, as opposed to SFC, offers the potential to reduce the economic burden of COPD in Singapore.

\section{ACKNOWLEDGEMENTS}

Tee A and Chow WL work at Changi General Hospital and Eastern Health Alliance, Singapore, respectively. Burke $C$ and Guruprasad B are employees of Novartis Ireland and Novartis Singapore, respectively. All authors were involved in reviewing and approving the manuscript. In addition, they were responsible for the adaptation of the cost-effectiveness model. This study was funded by Novartis Singapore Pte Ltd.

\section{REFERENCES}

1. Lozano R, Naghavi M, Foreman K, et al. Global and regional mortality from 235 causes of death for 20 age groups in 1990 and 2010: a systematic analysis for the Global Burden of Disease Study 2010. Lancet 2012; 380:2095-128.

2. Vos T, Flaxman AD, Naghavi M, et al. Years lived with disability (YLDs) for 1160 sequelae of 289 diseases and injuries 1990-2010: a systematic analysis for the Global Burden of Disease Study 2010. Lancet 2012; 380:2163-96.

3. Ministry of Health Singapore. Principal causes of death 2015. Available at: https://www.moh.gov.sg/content/moh_web/home/statistics/Health_Facts_ Singapore/Principal_Causes_of_Death.html. Accessed November 17, 2015.

4. Lim S, Lam DC, Muttalif AR, et al. Impact of chronic obstructive pulmonary disease (COPD) in the Asia-Pacific region: the EPIC Asia population-based survey. Asia Pac Fam Med 2015; 14:4.

5. Teo WS, Tan WS, Chong WF, et al. Economic burden of chronic obstructive pulmonary disease. Respirology 2012; 17:120-6.

6. Mapel DW, Dalal AA, Blanchette CM, Petersen H, Ferguson GT. Severity of COPD at initial spirometry-confirmed diagnosis: data from medical charts and administrative claims. Int J Chron Obstruct Pulmon Dis 2011; 6:573-81.

7. Global Initiative for Chronic Obstructive Lung Disease. Global strategy for diagnosis, management, and prevention of COPD - 2015. Available at: http:// goldcopd.org/. Accessed November 15, 2015

8. White P, Thornton H, Pinnock H, Georgopoulou S, Booth HP. Overtreatment of COPD with inhaled corticosteroids--implications for safety and costs: crosssectional observational study. PLoS One 2013; 8:e75221.

9. Price D, West D, Brusselle G, et al. Management of COPD in the UK primarycare setting: an analysis of real-life prescribing patterns. Int J Chron Obstruct Pulmon Dis 2014; 9:889-904.

10. Price D, Jones R, Gruffydd-Jones K, et al. Analyzing the pathway to triple therapy in COPD patients: a retrospective database analysis. Eur Respir J 2014; 44:P2411 (Abstract).

11. Vestbo J, Vogelmeier C, Small M, Higgins V. Understanding the GOLD 2011 Strategy as applied to a real-world COPD population. Respir Med 2014; 108:729-36.

12. Price D, Jones R, Gruffydd-Jones K, et al. Real-world prescribing patterns among newly diagnosed COPD patients receiving ICS: an analysis of UK patient dataset. Eur Respir J 2014; 44:P2422 (Abstract).

13. Miravitlles M, Sicras A, Crespo C, et al. Costs of chronic obstructive pulmonary disease in relation to compliance with guidelines: a study in the primary care 
setting. Ther Adv Respir Dis 2013; 7:139-50.

14. Price D, Brusselle G. Challenges of COPD diagnosis. Expert Opin Med Diagn 2013; 7:543-56.

15. Kew KM, Seniukovich A. Inhaled steroids and risk of pneumonia for chronic obstructive pulmonary disease. Cochrane Database Syst Rev 2014; 3:CD010115.

16. Suissa S, Kezouh A, Ernst P. Inhaled corticosteroids and the risks of diabetes onset and progression. Am J Med 2010; 123:1001-6.

17. Suissa S, Patenaude V, Lapi F, Ernst P. Inhaled corticosteroids in COPD and the risk of serious pneumonia. Thorax 2013; 68:1029-36.

18. Loke YK, Cavallazzi R, Singh S. Risk of fractures with inhaled corticosteroids in COPD: systematic review and meta-analysis of randomised controlled trials and observational studies. Thorax 2011; 66:699-708.

19. Vogelmeier CF, Bateman ED, Pallante J, et al. Efficacy and safety of once-daily QVA149 compared with twice-daily salmeterol-fluticasone in patients with chronic obstructive pulmonary disease (ILLUMINATE): a randomised, doubleblind, parallel group study. Lancet Respir Med 2013; 1:51-60.

20. Zhong N, Wang C, Zhou X, et al; LANTERN Investigators. LANTERN: a randomized study of QVA149 versus salmeterol/fluticasone combination in patients with COPD. Int J Chron Obstruct Pulmon Dis 2015; 10:1015-26.

21. Changi General Hospital. Available at: http://www.cgh.com.sg/Pages/Home. aspx. Accessed October 19, 2016

22. Ministry of Health Singapore. Costs and Financing. Available at: https://www moh.gov.sg/content/moh_web/home/costs_and_financing.html. Accessed October 19, 2016

23. Asukai $\mathrm{Y}$, Baldwin M, Fonseca $\mathrm{T}$, et al. Improving clinical reality in chronic obstructive pulmonary disease economic modelling: development and validation of a micro-simulation approach. Pharmacoeconomics 2013 31:151-61.

24. Price D, Keininger D, Costa-Scharplatz M, et al. Cost-effectiveness of the LABA LAMA dual bronchodilator indacaterol/glycopyrronium in a Swedish healthcare setting. Respir Med 2014; 108:1786-93.

25. Falaschetti E, Laiho J, Primatesta P, Purdon S. Prediction equations for norma and low lung function from the Health Survey for England. Eur Respir J 2004 23:456-63.

26. Quanjer PH, Tammeling GJ, Cotes JE, et al. Lung volumes and forced ventilatory flows. Report Working Party Standardization of Lung Function Tests, European Community for Steel and Coal. Official Statement of the European Respiratory Society. Eur Respir J Suppl 1993; 16:5-40.

27. Ministry of Health Singapore. Primary Care Survey 2010. Available at https://www.moh.gov.sg/content/dam/moh_web/Publications/Reports/2014/ Primary\%20Care\%20Survey\%202010\%20report.pdf. Accessed November 18 2015.

28. Price D, Gray A, Gale R, et al. Cost-utility analysis of indacaterol in Germany: a once-daily maintenance bronchodilator for patients with COPD. Respir Med 2011; 105:1635-47.

29. Foreign Exchange Rates - H.10. Available at: https://www.federalreserve.gov/ releases/h10/hist/dat00_si.htm. Accessed August, 2015.

30. Hurst JR, Vestbo J, Anzueto A, et al; Evaluation of COPD Longitudinally to Identify Predictive Surrogate Endpoints (ECLIPSE) Investigators. Susceptibility to exacerbation in chronic obstructive pulmonary disease. N Engl J Med 2010; 363:1128-38.

31. Husebø GR, Bakke PS, Aanerud M, et al. Predictors of exacerbations in chronic obstructive pulmonary disease--results from the Bergen COPD cohort study.
PLoS One 2014; 9:e109721.

32. Jenkins CR, Celli B, Anderson JA, et al. Seasonality and determinants of moderate and severe COPD exacerbations in the TORCH study. Eur Respir J 2012; 39:38-45.

33. Bowler RP, Kim V, Regan E, et al. Prediction of acute respiratory disease in current and former smokers with and without COPD. Chest 2014; 146:941-50.

34. Kerkhof M, Freeman D, Jones R, et al. Predicting frequent COPD exacerbations using primary care data. Int J Chron Obstruct Pulmon Dis 2015; 10:2439-50.

35. Wedzicha JA, Decramer M, Ficker JH, et al. Analysis of chronic obstructive pulmonary disease exacerbations with the dual bronchodilator QVA149 compared with glycopyrronium and tiotropium (SPARK): a randomised, doubleblind, parallel-group study. Lancet Respir Med 2013; 1:199-209.

36. Wedzicha JA, Banerji D, Chapman KR, et al. Indacaterol-glycopyrronium versus salmeterol-fluticasone for COPD. N Engl J Med 2016; 374:2222-34.

37. Dahl R, Chung KF, Buhl R, et al; INVOLVE (INdacaterol: Value in COPD: Longer Term Validation of Efficacy and Safety) Study Investigators. Efficacy of a new once-daily long-acting inhaled beta2-agonist indacaterol versus twice-daily formoterol in COPD. Thorax 2010; 65:473-9.

38. Donohue JF, Fogarty C, Lötvall J, et al; INHANCE Study Investigators. Oncedaily bronchodilators for chronic obstructive pulmonary disease: indacaterol versus tiotropium. Am J Respir Crit Care Med 2010; 182:155-62.

39. Feldman G, Siler T, Prasad N, et al; INLIGHT 1 study group. Efficacy and safety of indacaterol 150 microg once-daily in COPD: a double-blind, randomised, 12-week study. BMC Pulm Med 2010; 10:11

40. Rutten-van Mölken MP, Oostenbrink JB, Tashkin DP, Burkhart D, Monz BU. Does quality of life of COPD patients as measured by the generic EuroQol fivedimension questionnaire differentiate between COPD severity stages? Chest 2006; 130:1117-28

41. Department of Statistics Singapore. Complete life tables for 2014-2015 for Singapore resident population. Available at: http://www.singstat.gov.sg/docs/ default-source/default-document-library/publications/publications_and_papers/ births and deaths/lifetable14-15. Accessed November 18, 2015.

42. Lindberg A, Larsson LG, Muellerova H, Ronmark E, Lundbäck B. Up-to-date on mortality in COPD - report from the OLIN COPD study. BMC Pulm Med 2012; $12: 1$

43. World Health Organization. Cost-effectiveness and strategic planning (WHO-CHOICE). Available at: http://www.who.int/choice/cost-effectiveness/ generalized/en/. Accessed August 28, 2015.

44. The World Bank Group. GDP per capita (current US\$) 2014. Available at: http:// data.worldbank.org/indicator/NY.GDP.PCAP.CD. Accessed January 13, 2016.

45. Global initiative for Chronic Obstructive Lung Disease. GOLD 2017 Global Strategy for the Diagnosis, Management and Prevention of COPD. Available at: http://goldcopd.org/gold-2017-global-strategy-diagnosis-managementprevention-copd/. Accessed August 16, 2017.

46. Geitona M, Kousoulakou H, Kalogeropoulou M, et al. Cost-effectiveness analysis of the fixed combination indacaterol/glycopyrronium vs. tiotropium and salmeterol/fluticasone in the management of COPD in Greece. Value Health 2015; 18:A500.

47. Reza Maleki-Yazdi M, Molimard M, Keininger DL, et al. Cost effectiveness of the long-acting beta2-adrenergic agonist (LABA)/long-acting muscarinic antagonist dual bronchodilator indacaterol/glycopyrronium versus the LABA/inhaled corticosteroid combination salmeterol/fluticasone in patients with chronic obstructive pulmonary disease: analyses conducted for Canada, France, Italy, and Portugal. Appl Health Econ Health Policy 2016; 14:579-94. 